Communication

\title{
Radiation Balance of Urban Materials and Their Thermal Impact in Semi-Desert Region: Mexicali, México Study Case
}

\author{
Néstor Santillán-Soto ${ }^{1, *}$, Rafael García-Cueto ${ }^{1}$, Zalia Haro-Rincón ${ }^{2}$, Sara Ojeda-Benítez ${ }^{1}$, \\ Margarito Quintero-Núñez ${ }^{1}$ and Nicolás Velázquez-Limón ${ }^{1}$
}

1 Instituto de Ingeniería, Universidad Autónoma de Baja California, Blvd, Benito Juárez y calle de la Normal s/n. Col. Insurgentes Este, C.P. 21280, Mexicali, Baja California, Mexico; E-Mails: rafaelcueto@uabc.edu.mx (R.G.-C.); sara.ojeda.benitez@uabc.edu.mx (S.O.-B.); maquinu@uabc.edu.mx (M.Q.-N.); nicolas.velazquez@uabc.edu.mx (N.V.-L.)

2 Graduated of the Doctorate in Engineering Program, Instituto de Ingeniería, Universidad Autónoma de Baja California, Blvd, Benito Juárez y calle de la Normal s/n. Col. Insurgentes Este, C.P. 21280, Mexicali, Baja California, Mexico; E-Mail: zharo@uabc.edu.mx

* Author to whom correspondence should be addressed; E-Mail: nsantillan@uabc.edu.mx; Tel.: +52-686-566-4150 (ext. 132); Fax: +52-686-566-4150.

Academic Editor: Daniele Contini

Received: 6 August 2015 / Accepted: 14 October 2015 / Published: 23 October 2015

\begin{abstract}
Net radiation is an essential forcing of climate in the lower layers of Earth's atmosphere. In this paper, radiation balance is measured in clay soil and green grass, and is compared with three urban materials. These materials: asphalt, concrete and white painted elastomeric polystyrene roofing sheet are widely used in Mexicali, Baja California, México. This study was carried out during August of 2011, the hottest time of the year. The 24-hour average values of net radiation found were: $137.2 \mathrm{~W} \cdot \mathrm{m}^{-2}$ for asphalt, 119.1 for concrete, 104.6 for clay soil, 152 for green grass and 29.2 for the polystyrene insulation. The latter two types of materials are likely to be the most effective in reducing urban heat island effects. This variation in the radiation balance has widespread implications for human living conditions, as land cover change tends to be towards surfaces that have higher levels of net radiation.
\end{abstract}

Keywords: net radiation; longwave radiation; shortwave radiation; solar radiation; urban climate; urban coverage 


\section{Introduction}

The energy that is known as net radiation has a significant influence on thermal comfort and negative health affects on humans, because may impact upon the potential energy used for maintaining indoor living spaces comfortably, meaning additional thermal energy use due to external factors in the city urban configuration [1,2]. Net radiation is a fundamental variable that determines the climate of the lower layers of the atmosphere and is dependent on the physics and chemistry of the atmosphere as well as the presence of clouds. Other factors include surface characteristics, such as: albedo, emissivity, temperature, humidity and thermal properties of the underlying soil. In climate zones with extreme summers such as the arid South Western United States and Northwest of Mexico it is undesirable to add any anthropogenic energy contribution. Such anthropogenic energy due to land cover and land use change the available energy because the net radiation at the Earth's surface determines the amount of energy that can be used for physical and biological processes, such as evapotranspiration and air and soil warming [3-5].

Given the importance of this magnitude and its relation to landscape change, accurate measurements of net radiation are essential in studies of global and urban climate change. This net energy at the Earth's surface plays a significant role in the surface thermal conditions and energy balance [6]. Over any landscape, whether modified or urbanized, the use of net radiation as a critical variable in models of surface-atmosphere exchange is routine but its measurement is not [7]. Therefore, the use of solar sensors is one of the best allied tools for the study of landscape and land use changes because they can provide important results for other land cover applications, such as agriculture and forestry [8].

Land cover changes such as urban landscaping, agriculture crops or hard scapes for building and parking lots promote variations in the energy and radiation balance. Compared to rural or natural land cover, urban surface characteristics result in increased surface runoff, reduced latent heat flux and increased sensible heat flux to the urban atmosphere, all of which affect human comfort and activity $[9,10]$. Knowledge of how vegetation and land cover influence energy exchange processes and thus the urban climate is essential in forecasting how ecosystems will react and respond to future physical and biological disturbances as designed or unintended consequences [11]. In particular, urbanization is one of the most extreme ways in which humans alter land cover and land use, as it results in dramatic differences after cities have been established. Urbanization provokes the most complete transformations of land cover, generating a complex spatial surface materials mosaic that is in part driven by real estate marketing and the consequences of planning policies [12]. Nevertheless, any modifications to natural features, such as landforms, soils, vegetation and flows of energy and water are closely related to ecological and social factors.

Due to the above listed modifications, the surface temperatures and near-surface air temperatures over urban patches are generally higher than those over rural areas, thus resulting in an urban heat island (UHI) [13-15]. Some factors at the meso-scale contribute to the development of an UHI, whereas other UHIs are related to natural factors, such as weather and location. Other factors are related to human activity, such as urban geometry and materials, anthropogenic heat flux and deforestation [16,17]. All of the aforementioned factors may induce varying amounts of energy in the interface between the atmosphere and the urban surface. 
So in order to mitigate the effects of radiometric balance, i.e., the net energy, we have already documented that green roofs and cool roofs are commonly reported to provide urban heat mitigation potential, livability and sustainability of urban environments [18-20]. Consistently, Radhi et al. [21] found that white and light colored materials better cope with surface UHIs, that cool materials are beneficial in expanding solar regions and that materials with a low heat storage capacity are a significant atmospheric UHI reducer. This matches with the polystyrene results of this study. Additionally, Yahia and Johansson [22] reported an important effect caused by vegetation and landscape elements and their relationship with outdoor thermal comfort in a dry city; also, vegetation surface reduces ground night heat release and diurnal heat gain because it obstructs the flux of long-wave radiation between the urban surface and the lower atmosphere, even in cold cities [23]. These remarks coincide largely with the main findings from this research, especially the finding that insulated white roofs reflect most of the sunlight; they do not store energy and emit less heat both day and night, thus allowing less net energy in the lower atmosphere. For this reason, in this paper we are focusing on white painted elastomeric polystyrene roofing sheet and its urban climate benefits.

\section{Method}

To perform this research, the methodology was divided into two parts. In the first part, the design of the microclimate experiment was established. In the second, measurement campaigns were realized.

\subsection{Description of the Study Area}

This research was conducted in a semi-desert area located in northwestern Mexico, in the city of Mexicali, which is the capital of Baja California. Mexicali is located at $32.55^{\circ} \mathrm{N}, 115.47^{\circ} \mathrm{W}$ and four meters above sea level and experiences average July high temperatures of $42.2^{\circ} \mathrm{C}$ and average January high temperatures of $21.1^{\circ} \mathrm{C}$. The population of Mexicali is 936,826 inhabitants [24,25]. In general this is an area with extreme climate conditions that are dominant both in northwestern Mexico and in the southwestern United States. The estimated 2030 population is 1,276,000 [26], a growth that indicates the importance of this research on urban radiation balance change.

\subsection{Materials}

One option to analyze the impact to the urban climate due to urban infrastructure is through the measuring of radiometric balance that can be performed with the radiometer NR01, an instrument that serves to measure the four separate components of the surface radiation balance, and has a high research degree reference compared with conventional past-generation net sensors. Net all-wave radiation $\left(\mathrm{Q}_{\mathrm{N}}\right)$ consists of the balance of four radiation components in two wavelength bands: $\mathrm{Q}_{\mathrm{N}}=\mathrm{K}_{\mathrm{N}}+\mathrm{L}_{\mathrm{N}}=(\mathrm{K} \downarrow+\mathrm{K} \downarrow)+(\mathrm{L} \downarrow+\mathrm{L} \uparrow)$, where $\mathrm{K}_{\mathrm{N}}$ and $\mathrm{L}_{\mathrm{N}}$ represent net shortwave radiation and net longwave radiation, and $\mathrm{K} \downarrow, \mathrm{K} \uparrow, \mathrm{L} \downarrow$ y $\mathrm{L} \uparrow$ are the downward shortwave radiation, upward shortwave radiation, downward longwave radiation and upward longwave radiation, respectively. The arrows denote the direction of the radiation flux densities: components transporting energy to the surface are positive, and those removing energy are negative: [27]. A CR3000 datalogger (Campbell Sci. Logan Utah, U.S.A.) was programmed to register the data from the sensor. To identify the materials used, the 
following abbreviations were used: native land (clay), asphalt (asp), concrete (con), grass and expanded polystyrene with white elastomeric paint (poly). The urban surface materials analyzed are described in Table 1.

Table 1. Coverage materials and measurement dates. Summer season.

\begin{tabular}{cc}
\hline Material & Measurements Dates \\
\hline Clay & $5-7$ August 2011 \\
Asp & $9-11$ August 2011 \\
Con & $12-14$ August 2011 \\
Poly & $18-20$ August 2011 \\
Grass & $24-26$ August 2011 \\
\hline
\end{tabular}

\subsection{Experimental Design}

The design for measuring radiation balance consisted a wooden box measuring $1 \mathrm{~m} \times 1 \mathrm{~m} \times 0.55 \mathrm{~m}$ deep to hold the materials to be tested. The construction of the box was made of wood because it has a low thermal conductivity value thus minimizing the thermal influence of the box boundary. Clay was evaluated first, and after urban land cover specimens of $1 \mathrm{~m} \times 1 \mathrm{~m}$ were placed over this clay to be measured too. The studied materials included concrete, asphalt, grass and an expanded polystyrene sheet (0.05-m-thick) painted with elastomeric waterproof coating. The last material is widely used in Mexicali for roof insulation. Figure 1 shows the experimental arrangement.
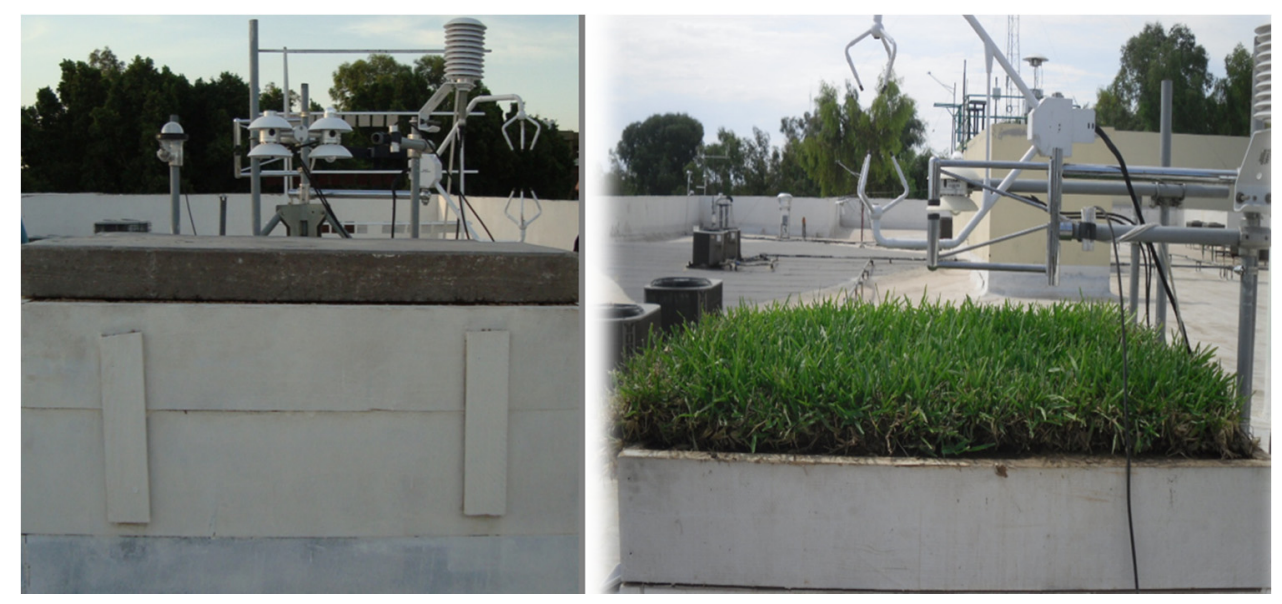

Figure 1. Experimental setting for tests Concrete (left) and grass (right).

\subsection{Collection of Data}

The four-component net radiation sensor NR01 was placed on the studied cover materials at a height of $0.20 \mathrm{~m}$ in the center of each specimen to obtain the visual range of the sensor regarding $1 \mathrm{~m}^{2}$ of each material placed. Shadowing effects, due to short distance between sensor and the surfaces, are the same throughout the experiment, its influences are constant and could slightly modify the magnitude but not the behavior. All five materials were tested in clear days for two days and then the second material for two days and so on. Sampling was every 5 minutes and those values were averaged 
every hour during the day. Another set of readings was taken during the next 24 hours to replicate, compare and obtain two representative days and was averaged for a single day.

\section{Results}

The data were grouped by radiative components. High values for this semi-arid location are recorded because of the sunny days [28,29]. Figure 2a shows the downward shortwave radiation and Figure $2 \mathrm{~b}$ displays the upward shortwave radiation. The greatest percentage of reflection is exhibited by poly material due to its surface and insulation characteristics (Figure 2b), whereas the dark coverage of the asphalt absorbs highest quantities of radiation. The explanation of Figure $2 \mathrm{c}$ is that the atmosphere traps the energy emitted by the Earth and returns it to the planet surface in longwave, a phenomenon known as the greenhouse effect. At any particular time and place, $L \downarrow$ is controlled by cloud cover, cloud type and depth, as well as ambient values of vapor pressure, temperature and atmospheric precipitable water [30]. Regarding the upward longwave of each surface (Figure 2d), poly and grass demonstrate similar behaviors and both emit the lowest thermal radiation. However, clay and asphalt surfaces emit infrared radiation with higher values.
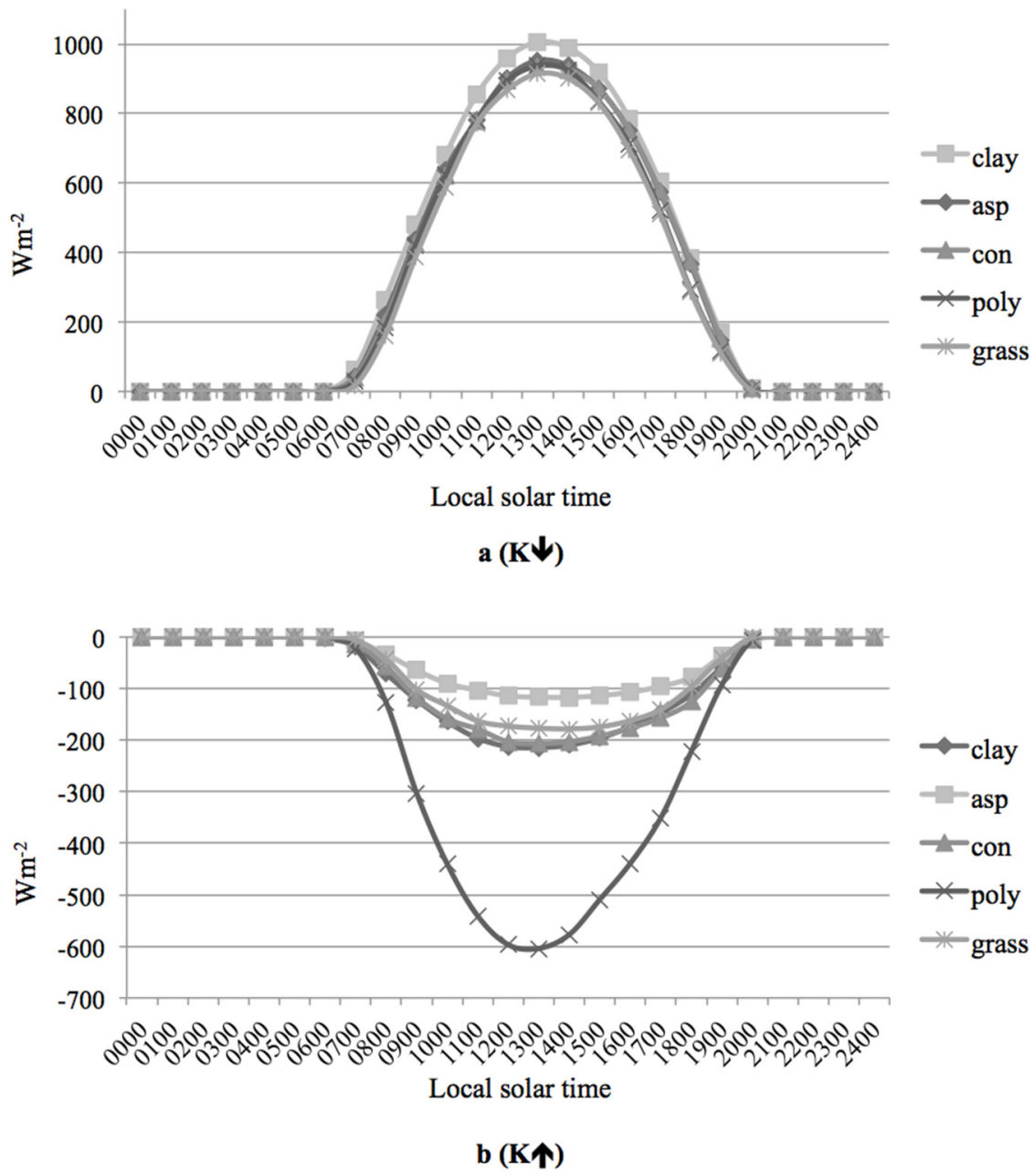

Figure 2. Cont. 

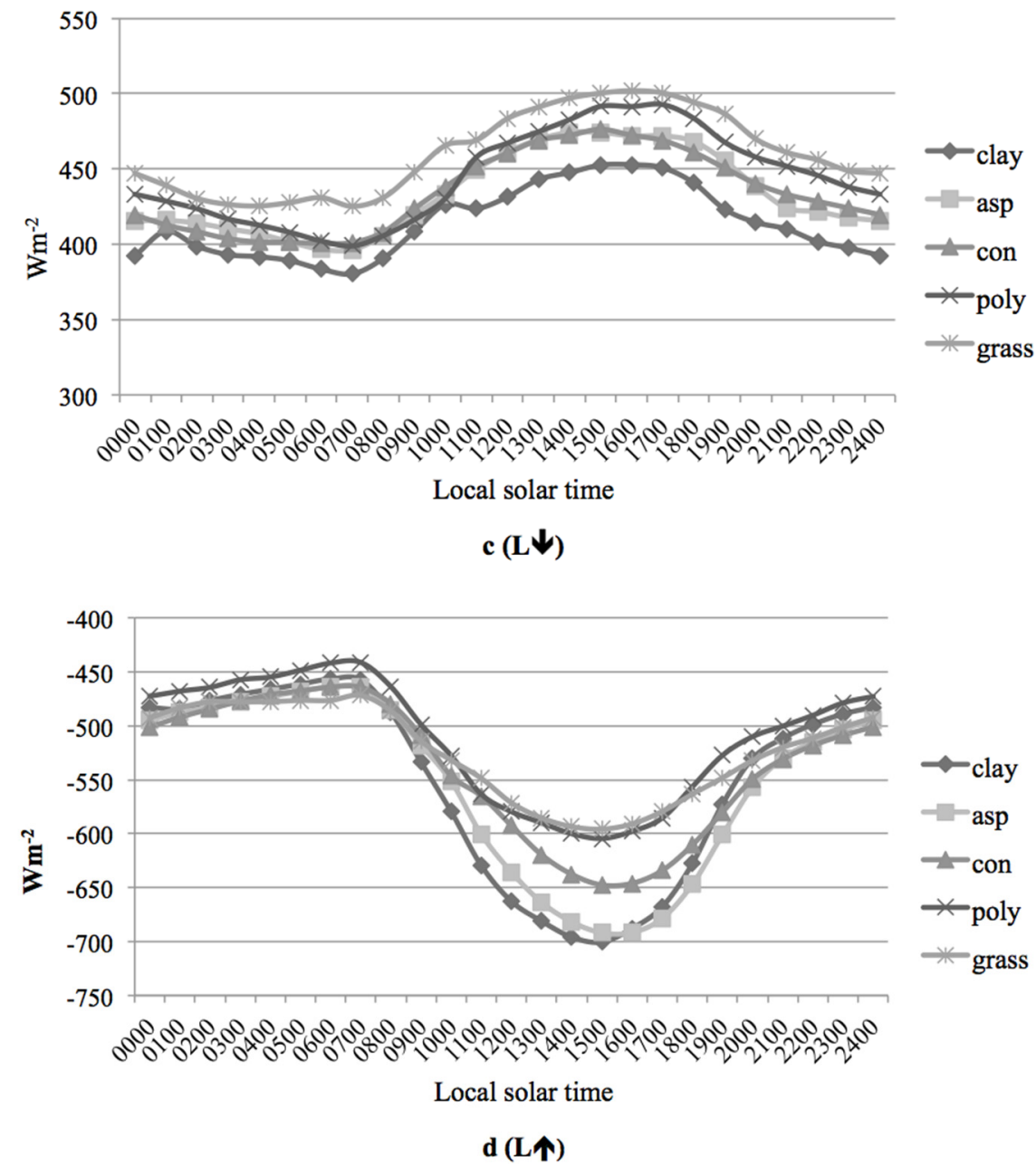

Figure 2. Solar radiation flux: downward shortwave (a), upward shortwave (b), downward longwave (c) and upward longwave (d).

Finally, Figure 3 shows the net radiation $\left(\mathrm{R}_{\mathrm{N}}\right)$. When considering all materials studied, this variable is smallest for poly.

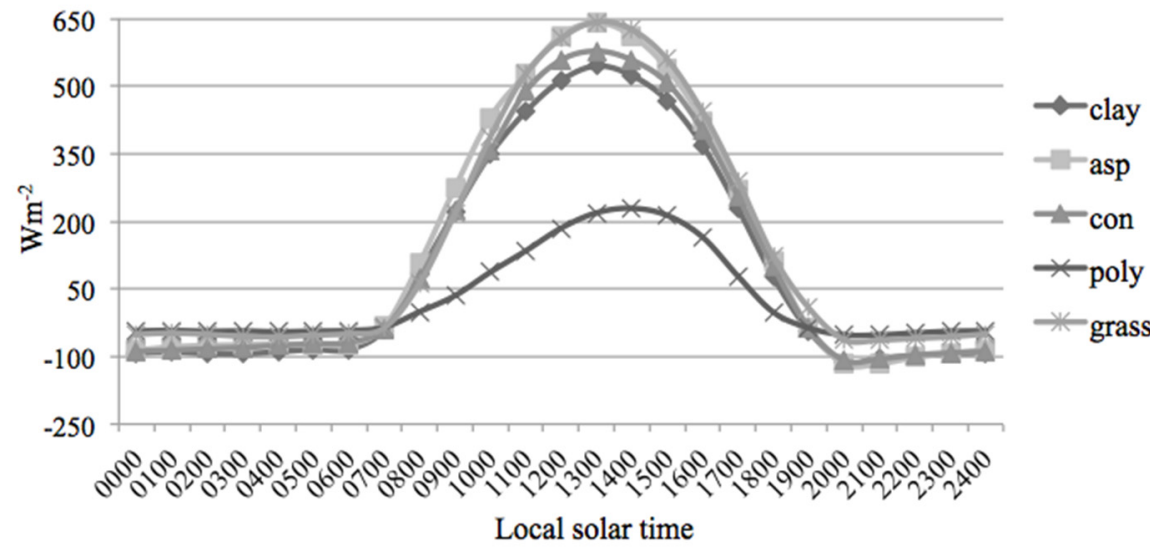

Figure 3. Net radiation flux resulting from each material $\left(\mathrm{Q}_{\mathrm{N}}\right)$.

The results allow for comparisons and analysis. Figure $2 \mathrm{a}$ indicates that the weather on each day of testing was sunny with $\mathrm{K} \downarrow$ reaching $1000 \mathrm{~W} \cdot \mathrm{m}^{-2}$. The results highlight that the material that reflects 
the most shortwave energy over a 24-hour average is poly $\left(-193.37 \mathrm{~W} \cdot \mathrm{m}^{-2}\right)$, whereas the least reflecting material was asphalt $\left(-43.61 \mathrm{~W} \cdot \mathrm{m}^{-2}\right)$. As shown in Figure $2 \mathrm{~b}$ and Table 2, the materials surfaces reflect solar radiation in the following ascending order: asphalt, grass, concrete, clay and poly. The last material exhibits pronounced differences from the other four specimens and reflects $66 \%$ of the downward radiation, whereas clay and concrete are in the same order $(23 \%$ and $25 \%)$ and at the end asphalt with $14 \%$ (Table 5). Asphalt is the coverage that reflects the least solar radiation, and thus, it is one of the urban materials that store the most energy. This energy is then re-emitted as heat during the night, thus contributing significantly to the formation of urban heat islands [31]. On the other hand, poly and grass are the surfaces that contribute the least amount of thermal energy during a 24-hour average (Figure 2d). It is further noted that, although the averages of upward longwave radiation are between -511.77 and $-554.29 \mathrm{~W} \cdot \mathrm{m}^{-2}$, the lowest longwave energy emissions were obtained with poly and grass, and the lowest $\mathbf{Q}_{\mathbf{N}}$ flux was reported for the insulation surface, i.e., $29.28 \mathrm{~W} \cdot \mathrm{m}^{-2}$ (Table 2).

Table 2. NR01 solar components and net total radiation in $\mathrm{W} \cdot \mathrm{m}^{-2}$.

\begin{tabular}{cccccc}
\hline Material & $\mathbf{K} \downarrow$ & $\mathbf{K} \uparrow$ & $\mathbf{L} \downarrow$ & $\mathbf{L} \uparrow$ & $\mathbf{Q}_{\mathbf{N}}$ \\
\hline Clay & 326.70 & -76.38 & 413.77 & -551.76 & 104.61 \\
Asphalt & 305.26 & -43.61 & 433.13 & -554.29 & 137.29 \\
Concrete & 302.47 & -74.47 & 433.82 & -539.87 & 119.14 \\
Poly & 291.24 & -193.37 & 444.43 & -511.77 & 29.28 \\
Grass & 281.51 & -63.83 & 460.08 & -523.94 & 152.06 \\
\hline
\end{tabular}

This conclusion may be associated with the thermal properties of these materials in that asphalt has high heat capacity and low diffusivity. Moreover, the poly surface exhibits exceptionally low heat capacity because it is an insulator and its diffusivity is high (Table 3) [32]. These thermal characteristics are desirable in pavements and cool roofs to mitigate the effects of heat islands in urban environment [33].

Table 3. Thermal properties of materials.

\begin{tabular}{cccc}
\hline Material & $\begin{array}{c}\text { Conductivity } \\
\mathbf{W} \cdot \mathbf{m}^{\mathbf{- 1}} \cdot \mathbf{K}^{\mathbf{- 1}}\end{array}$ & $\begin{array}{c}\text { Heat Capacity } \\
\mathbf{J} \cdot \mathbf{m}^{-\mathbf{3}} \mathbf{K} \times \mathbf{\mathbf { 1 0 } ^ { \mathbf { 3 } }}\end{array}$ & $\begin{array}{c}\text { Diffusivity } \\
\mathbf{m}^{\mathbf{2}} \cdot \mathbf{s}^{\mathbf{1}} \times \mathbf{1 0 ^ { \mathbf { 6 } }}\end{array}$ \\
\hline Clay & 0.25 & 1.42 & 0.18 \\
Asphalt & 0.75 & 1.94 & 0.38 \\
Concrete & 1.51 & 2.11 & 0.72 \\
Exp. Poly. & 0.03 & 0.02 & 1.5 \\
Grass & - & - & - \\
\hline
\end{tabular}

Table 4 displays the four components normalized with respect to the net radiation energy during each experiment. It can be observed that $\mathrm{K} \downarrow$ is almost 10 times greater than the $\mathbf{Q}_{\mathbf{N}}$ (Table 2, $291.24 / 29.28=9.94$ ) for poly. This surface reflects the higher value (Table 3, 193.37/29.28=6.60). Furthermore, this material has a high rate of thermal emission from its available low net radiation (Table 2, $-511.77 / 29.28=17.47$ ). 
Table 4. Average of NR01 components divided by $\mathbf{Q}_{\mathbf{N}}$.

\begin{tabular}{ccccc}
\hline Material & $\mathbf{K} \downarrow / \mathbf{Q}_{\mathbf{N}}$ & $\mathbf{K} \uparrow / \mathbf{Q}_{\mathbf{N}}$ & $\mathbf{L} \downarrow / \mathbf{Q}_{\mathbf{N}}$ & $\mathbf{L} \uparrow / \mathbf{Q}_{\mathbf{N}}$ \\
\hline Clay & 3.12 & -0.73 & 3.95 & -5.27 \\
Asphalt & 2.22 & -0.31 & 3.15 & -4.03 \\
Concrete & 2.53 & -0.62 & 3.64 & -4.53 \\
Poly & 9.94 & -6.60 & 15.17 & -17.47 \\
Grass & 1.85 & -0.41 & 3.02 & -3.44 \\
\hline
\end{tabular}

As could be observed in Table 5, the columns that identify the largest differences are $\mathrm{K} \uparrow / \mathrm{K} \downarrow$ and $\mathbf{Q}_{\mathbf{N}} / \mathrm{K} \downarrow$, especially for poly because these ratios depend mainly on the downward shortwave component.

Table 5. Average of NR01 components divided by K $\downarrow$.

\begin{tabular}{ccccc}
\hline Material & $\mathbf{K} \uparrow / \mathbf{K} \downarrow$ & $\mathbf{L} \downarrow / \mathbf{K} \downarrow$ & $\mathbf{L} \uparrow / \mathbf{K} \downarrow$ & $\mathbf{Q} \mathbf{N} / \mathbf{K} \downarrow$ \\
\hline Clay & -0.23 & 1.27 & -1.69 & 0.32 \\
Asphalt & -0.14 & 1.42 & -1.82 & 0.45 \\
Concrete & -0.25 & 1.43 & -1.78 & 0.39 \\
Poly & -0.66 & 1.53 & -1.76 & 0.10 \\
Grass & -0.23 & 1.63 & -1.86 & 0.54 \\
\hline
\end{tabular}

\section{Discussion}

At this point the discussion could be focused on the components that explain the materials behavior in short time due to its prompt response, i.e., the shortwave components $\mathrm{K} \downarrow$ and $\mathrm{K} \uparrow$. The longwave radiation is difficult to analyze in short cycles and is very complex for some aspects among them advective influences, surrounding surfaces, thermal materials properties, but despite these mentioned aspects we can deduce from Table 2 that the averages -511.77 and -523.94 and the mathematical model of Stefan-Boltzmann, that surface temperatures for poly and grass were the lowest of all tested materials because upward longwave flux is a function of emissivity and surface temperature. Downward longwave is a function of the atmosphere condition and therefore long period analyses are necessary to explain its impact. Since the measurements dates are not same, the values of $\mathrm{K} \downarrow$ and $\mathrm{L} \downarrow$ have differing initial values. Nevertheless, when a t-test is carried out, the mean difference $(0.05$ significance level) between the values of the downward shortwave radiation indicates no significant statistical difference. Measurements of the downward longwave radiation exhibited no significant difference in the measurements of asphalt, concrete, and poly. Even so differences were found between grass and clay. As was mentioned before, measurements were taken during clear days, but there are factors such as water vapor content and atmospheric aerosols (GHG) that may have a contribution to the differences. Figures 2 and 3 present the radiation balance of each surface, where these figures have a similar behavior respect to daily pattern of $\mathrm{K} \downarrow$, and $\mathrm{Q}_{\mathrm{N}}$, with the highest records at solar midday for most surfaces. Withal, poly surfaces in terms of $Q_{N}$ differ with respect to the rest materials tested, by the smallest value and the delay time at its maximum value. Upward shortwave radiation $\mathrm{K} \uparrow$, as a function of reflectivity, shows a diurnal behavior dependent on the subjacent surface and the angle of inclination of the solar rays. Upward and downward longwave radiation does not show the 
characteristic waveform of the other fluxes and display slightly more variation in the upward longwave radiation.

Despite that the experimentation was realized in different days, the results shown are clear about what each surface brings to the shortwave radiation because the behavior of the upward component depends on the irradiation and reflectance. In order to deepen the analysis of each radiative component in their respective day of experimentation, each was normalized respect to $Q_{N}$ and $K_{\downarrow}$. We can see that for each component poly acquires a very high proportion of $\mathrm{Q}_{\mathrm{N}}$ (Table 4) and moreover, only $\mathrm{K} \uparrow / \mathrm{K} \downarrow$ has a very high ratio and $\mathbf{Q}_{\mathbf{N}} / \mathrm{K} \downarrow$ a very low ratio (Table 5).

The results indicate that, after the radiative balance was calculated, the material with the least net energy was the most highly reflective material (poly). Contrary to this, the materials with the greatest amount of net flux were the least reflective materials (asphalt, concrete and clay). This finding is consistent with the data presented in Figure 2d, Figure 3 and the tables presented. Poly was also relevant in a previous study in which all net energy became sensible heat flux mainly $\left(\mathrm{Q}_{\mathrm{N}}=\mathrm{Q}_{\mathrm{h}}\right)$ [34]. Grass represents a heat sink because it has the lowest thermal emission values (Table 4 and Figure 2d).

This research has been developed at a micro scale with some limitations due to the set-up of arrangement experimental. The next step in this research study will be to repeat the testing in this same city, at a period of 30 days, on a larger scale $\left(92,700 \mathrm{~m}^{2}\right)$, this will require cranes to install the radiometric sensor at a height of 20 meters on a complex of 306 houses with white roofs (32\% of insulated and waterproofed with elastomeric white paint) in which the houses have the same design and will be compared with an old urbanized area with heterogeneous surfaces and houses designs (172 houses with the same grid of $92,700 \mathrm{~m}^{2}$ and $14 \%$ of white-insulated roofs). Additionally, eddy covariance and thermography equipment will be installed. The simultaneity of the proposal study will minimize uncertainties in longwave components, the effects of shading by radiometric sensor positioning, and advective influences will may discussed on the new study areas. So, the new findings would help planners and designers to minimize the thermal impact in Mexicali.

\section{Conclusions}

In summary, a suitable combination of poly and grass (or green bodies) with other urban materials could help to minimize the urban thermal impact, such as the urban heat island, because both emit less outgoing longwave radiation. In particular, poly is a convenient way to increase the surface reflectance of the city and can be a compensating factor to minimize the thermal impact due to dense materials such as asphalt and concrete. It is evident that more measurements with NR01 are necessary because the observations are definitely rather too short to issue a recommendation on the most suitable materials for further urbanizing in Mexicali.

\section{Acknowledgments}

The authors are grateful to Professional Development Program for Teachers (PRODEP) the federal resource given to conduct this project. 


\section{Author Contributions}

Néstor Santillán-Soto was the main researcher for this project. Rafael García-Cueto advised the study from planning, to completion and publications. Zalia Haro-Rincón obtained her doctoral degree as a student of this project. Sara Ojeda-Benítez participates in the development and structure of this manuscript. Margarito Quintero-Núñez and Nicolás Velázquez-Limón participated with contributions in the methodology.

\section{Conflicts of Interest}

The authors declare no conflict of interest.

\section{References}

1. Steeneveld, G.J.; Koopmans, S.; Heusinkveld, B.G.; Theeuwes, N.E. Refreshing the role of open water surfaces on mitigating the maximum urban heat island effect. Lands. Urban. Plan. 2014, 121, 92-96.

2. Shahidan, M.F.; Shariff, M.K.M.; Jones, P.; Salleh, E.; Abdullah, A.M. A comparison of Mesua ferrea L. and Hura crepitans L. for shade creation and radiation modification in improving thermal comfort. Lands. Urban. Plan. 2010, 97, 168-181.

3. Kalthoff, N.; Fiebig-Wittmaack, M.; MeiBner, C.; Kohle,r M.; Uriarte, M.; Bischoff-Gau, B.I.; Gonzalez, E. The energy balance, evapo-traspiration and nocturnal dew deposition of an arid valley in the Andes. J. Arid Environ. 2006, 65, 420-443

4. Geraldo-Ferreira, A.; Soria-Olivas, E.; Gómez-Sanchis, J.; Serrano-López, A.J.; Velázquez-Blazquez, A.; López-Baeza, E. Modelling net radiation at surface using "in situ" netpyrradiometer measurements with artificial neural networks. Expert Syst. Appl. 2011, 38, 14190-14195.

5. Hye-Yun, K.; Shunlin, L. Development of a hybrid method for estimating land surface shortwave net radiation from MODIS data. Rem. Sens. Environ. 2010, 114, 2393-2402.

6. Blonquist, J.M.; Tanner, B.D.; Bugbee, B. Evaluation of measurement accuracy and comparison of two new and three traditional net radiometers. Agr. For. Meteorol. 2009, 149, 1709-1721.

7. Cobos, D.R.; Baker, J.M. Evaluation and modification of a domeless net radiometer. Agron. J. 2003, 95, 177-183.

8. Pajares, G. Advances in Sensors Applied to Agriculture and Forestry. Sensors 2011, 11, 8930-8932.

9. Järvi, L.; Grimmond, C.S.B.; Christen, A. The Surface Urban Energy and Water Balance Scheme (SUEWS): Evaluation in Los Angeles and Vancouver. J. Hydrol. 2011, 411, 219-237.

10. Feyisa, G.L.; Dons, K.; Meilby, H. Efficiency of parks in mitigating urban heat island effect: An example from Addis Ababa. Lands. Urban. Plan. 2014, 123, 87-95.

11. Krishnan, P.; Meyers, T.P.; Scott, R.L.; Kennedy, L.; Heuer, M. Energy exchange and evapotranspiration over two temperate semi-arid grasslands in North America. Agr. For. Meteorol. 2012, 153, 31-44. 
12. Wrenn, D.H.; Sam, A.G. Geographically and temporally weighted likelihood regression: Exploring the spatiotemporal determinants of land use change. Reg. Sci. Urban. Econ. 2014, 44, 60-74.

13. Mackey, C.W.; Lee, X.; Smith, R.B. Remotely sensing the cooling effects of city scale efforts to reduce urban heat island. Build. Environ. 2012, 49, 348-358.

14. Yuan-Fong, S.; Foodya, G.M.; Ke-Sheng, C. Spatial non-stationarity in the relationships between land cover and surface temperature in an urban heat island and its impacts on thermally sensitive populations. Lands. Urban. Plan. 2012, 107, 172-180.

15. Zhang, N.; Wang, X.; Peng, Z. Large-Eddy simulation of mesoscale circulations forced by inhomogeneous urban Heat Island. Boundary-Layer Meteorol. 2013, 151, 179-194.

16. Radhi, H.; Fikry, F.; Sharples, S. Impacts of urbanization on the thermal behaviour of new built up environments: A scoping study of the urban heat island in Bahrain. Lands. Urban. Plan. 2013, $113,47-61$.

17. Groleau, M.; Mestayer, P.G. Urban morphology influence on urban albedo: A revisit with the solene model. Bound.-Layer Meteorol. 2012, 147, 301-327.

18. Coutts, A.M.; Daly, E., Beringer, J.; Tapper, N. Assessing practical measures to reduce urban heat: Green and cool roofs. Build. Environ. 2013, 70, 266-276.

19. Klein, P.M.; Coffman, R. Establishment and performance of an experimental green roof under extreme climatic conditions. Sci. Total Environ. 2015, 512-513, 82-93.

20. Razzaghmanesh, M.; Beecham, S.; Kazemi, F. The growth and survival of plants in urban green roofs in a dry climate. Sci. Total Environ. 2014, 476-477, 288-297.

21. Radhi, H.; Assem, E.; Sharples, S. On the colours and properties of building surface materials to mitigate urban heat islands in highly productive solar regions. Build. Environ. 2014, 72, 162-172.

22. Yahia, M.W.; Johansson, E. Landscape interventions in improving thermal comfort in the hot dry city of Damascus, Syria-The example of residential spaces with detached buildings. Lands. Urban. Plan. 2014, 125, 1-16.

23. Wang, Y.; Akbari, H. Effect of sky view factor on outdoor temperature and comfort in Montreal. Environ. Eng. Sci. 2014, 31, 272-287.

24. Santillán-Soto, N.; García-Cueto, O.R.; Ojeda-Benítez, S.; Velázquez-Limón, N.; Quintero-Núñez, M.; Schorr, M. Greenhouse gases mitigation against climate change: Unites States-Mexico border study case. Atmosfera 2013, 26, 499-507.

25. García-Cueto, O.R.; Santillán-Soto, N.; Quintero-Núñez, M.; Ojeda-Benítez, S.; Velázquez-Limón, N. Extreme temperature scenarios in Mexicali, México under climate change conditions. Atmosfera 2013, 26, 509-520.

26. CONAPO. Consejo Nacional de Población. Proyecciones de la Población en México 2005-2050. Available online: http://www.portal.conapo.gob.mx/index.php?option=com_content\&view $=$ article \&id=36\&Itemid=294 (accessed on 30 January 2015).

27. Christen, A.; Vogt, R. Energy and radiation balance of a central European city. Int. J. Climatol. 2004, 24, 1395-1421.

28. García-Cueto, O.R.; Santillán-Soto, N. Modeling extreme climate events: Two case studies in México. In Climate Models; Druyan, L.M., Ed.; Intech: Rijeka, Croatia, 2012; p. 145. 
29. García-Cueto, O.R.; Cavazos, M.T.; De Grau P.; Santillán-Soto, N. Analysis and modeling of extreme temperatures in several cities in northwestern Mexico under climate change conditions. Theor. Appl. Climatol. 2014, 116, 211-225.

30. Marthews, T.R.; Malhi T.; Iwata, H. Calculating downward longwave radiation under clear and cloudy conditions over a tropical lowland forest site: An evaluation of model schemes for hourly data. Theor. Appl. Climatil. 2012, 107, 461-477.

31. Synnefa, A.; Karlessi, T.; Gaitani, N.; Santamouris, M.; Assimakopoulos, D.N.; Papakatsikas, C. Experimental testing of cool colored thin layer asphalt and estimation of its potential to improve the urban microclimate. Build. Environ. 2011, 46, 38-44.

32. Oke, T.R. Boundary Layer Climates, 2nd ed.; Routledge: London, UK, 1987.

33. Climate Protection Partnership Division in the U.S. Environmental Protection Agency's Office of Atmospheric Programs. Reducing Urban Heat Islands: Compendium of Strategies Cool Pavements, 2012. Available online: http:/www.epa.gov/heatislands/resources/pdf/ CoolPavesCompendium.pdf (accessed on 21 May 2015).

34. Haro-Rincón, Z.; Santillán-Soto, N.; García-Cueto, N.; Ojeda-Benítez, S.; Lambert-Arista, A. Microclimatic experimentation applied to insulating horizontal coverage in Mexicali, Mexico. $J$. Environ. Sci. Eng. 2013, A2, 561-568.

(C) 2015 by the authors; licensee MDPI, Basel, Switzerland. This article is an open access article distributed under the terms and conditions of the Creative Commons Attribution license (http://creativecommons.org/licenses/by/4.0/). 